\title{
THE USE OF AN ONLINE LEARNING PLATFORM: A STEP TOWARDS E-LEARNING
}

\author{
P. Mashau* \\ Graduate School of Business and Leadership \\ e-mail: pm.mashau@gmail.com / https://orcid.org/0000-0003-0490-1925
}

\section{J. C. Nyawo*}

Discipline of Public Governance

e-mail: nyawoj1@ukzn.ac.za / https://orcid.org/0000-0003-3502-1680

*University of KwaZulu-Natal

Durban South Africa

\section{ABSTRACT}

In South Africa for the last few years, the Higher Education Institutions (HEls) have experienced unforeseen events that have eventually led to universities' suspension of academic activities. This has financial implications and leads to the extension of the academic calendar. This article looks at using an online learning platform to respond to unforeseen circumstances and beyond this, a shift to the new mode of university service delivery. The article presents the collective perspective of selected students of the School of Governance at the University of KwaZulu-Natal, South Africa. This quantitative study used a census approach of collecting data from the defined population. A total of 212 questionnaires were distributed to students, of which 107 were completed and returned.

E-learning is currently a common topic of conversation and will continue to be so in the wake of the current worldwide COVID-19 pandemic. This study suggests that there is a need to improve students' experiences of using online learning platforms and doing online assessments to roll out online teaching and learning successfully. The results also suggest that the facilitators need to rethink their teaching pedagogy in the process of shifting to e-learning.

Key words: Coronavirus, e-learning, online learning platform, pedagogy

\section{INTRODUCTION}

The world is full of uncertainty and South African Higher Education Institutions (HEIs) have not been spared in their exposure to unforeseen events. Harnessing the opportunities that come with the benefits of the fourth industrial revolution has been a challenge to many organisations and individuals, particularly students. Xing and Marwala $(2017,10)$ contextualise the "status quo of society as one in which graduates face a world transformed by technology, in which the Internet, cloud computing and social media create different opportunities and challenges for 
formal education systems". The outbreak of the novel Coronavirus (COVID-19) has further affected South African higher education, leading to the complete closure of universities. However, the closure of HEI has opened a new dialogue at both the ministerial level and institutional level about the preparedness of higher education institutions to use digital platforms. Several challenges which have arisen signify that HIEs in South Africa are not entirely ready to conduct learning through online platforms. In the haze of this situation, students struggle to connect to the Internet, use a computer, and contextualise the digital economy, in general. Therefore, this study investigates selected undergraduate students' perceptions toward e-learning and assesses if students are ready to learn through digital platforms. This is a case study of the Discipline of Governance at the University of KwaZuluNatal (UKZN). This particular institution has experienced recurrent student protests and recently the outbreak of the novel Coronavirus (COVID-19), resulting in country-wide lockdown, the closure of all except essential services, and the restriction of travel. This has led to the suspension of the academic programme and has brought traditional student-lecturer interaction to a complete halt.

The following sections show that effective pedagogy, students' and lecturers' literacy, and online content are required for successful delivery of online learning. This study makes use of the Technological Pedagogical Content Knowledge (TPCK) framework.

\section{LITERATURE REVIEW}

Technology is not easily accepted by users, nor is change. Mashau (2017) suggests the adoption of the technology acceptance model in HEIs in order to holistically consider the implication of technology for students and lecturers. There is a need to carefully strategise the implementation of the use of technology to maximise the benefits. Mashau, Fields and Nyawo (2019) strongly suggest collaboration between government, industry and academia. In order to make the university innovative, there is a greater need for interconnectedness during a crisis or change process. Teaching and learning involve the connections between facilitators, students and the relevant theme or content matter. Numerous factors influence the effectiveness of teaching and learning. Among others, such factors include the "course design and how the interactions meet the needs of the students to achieve personal goals and specific course outcomes" (Jordaan and Van der Merwe 2015, 54). The following sub-section provides the literature review on technology and online assessments as teaching and learning tools. 


\section{Educational technology}

Today's expeditiously environment and continuous changes in technology, the emergence of sophisticated teaching and learning tools and systems have the most remarkable positive developmental impact on the way students learn, communication of the information to the students, and the design and format of the syllabus (Al-Khalifa 2010; Ruxwana and Msibi 2018). The modern trends in education technology have led many universities to utilise online learning (e-learning), which largely depends on the utilisation of the Internet and computers for teaching and learning processes. According to Al-zabun (2015, 70), e-learning means depending on "modern technologies to deliver students' learning content effectively with positive characteristics". These positive characteristics include saving more effort, time and economical cost; and promoting and improving student learning.

Furthermore, Al-Rifaee $(2018,30)$ states that e-learning also "provides an exciting and inspiring learning environment which is stimulating for teachers and students, as the determinants of time and space are eliminated in addition to allowing students to learn in light of their capabilities and scientific abilities and levels of knowledge". In all aspects of people's lives, the uprising of the information superhighway and telecommunication technologies has had influences (Eljinini et al. 2012). Rooney (2003); Dobrzaski, Brytan, and Brom (2007); Ting-Sheng Weng and Lin (2007); Weaver, Spratt, and Nair (2008); and Gorghiu et al. (2009), have indicated that the application of information and communications technology in numerous higher education institutions around the world in the process of teaching and learning, has been increasing. Alruwais, Wills and Wald $(2018,34)$ also emphasised that "information and communication technology has been an assistance tool in education for a long time”. Therefore, the rapidly changing trends and developments in the field of technologies have forced the universities to change the visions of their educational programs offered to the students, in order to stay relevant, as "e-learning is becoming one of the teachings and learning standards in many universities" (Eljinini et al. 2012, 76).

Within the current digital age, the higher education institutions in South Africa are experiencing numerous impediments in the provision of effective teaching and learning practices. Some of the obstacles affecting teaching and learning include socio-economic factors, infrastructure shortage, technology instability, technological cost, lecturer efforts, lack of online learning culture, students' vexation with online learning, inadequate ITC skills and students' under-preparedness for higher education learning institutions (Mlitwa and Van Belle 2011; Venter et al. 2012; Isabirye and Dlodlo 2014; OERAfrica 2014). While such obstacles exist, the facilitators within the higher education institutions are being "challenged to utilise digital technologies in the education setting to effectively facilitate deliberative events in which 
students can critically engage with one another" (Wankle 2011,3).

As South African higher education institutions work towards a common goal within the context of global education transformation, the use of and need for learning technologies or elearning tools are of paramount importance. The position of the Department of Higher Education and Training (DHET), which is highlighted in the White Paper for Post-School Education and Training concerning digital learning, focuses mostly on the growth of satellite learning and online distance education, including online educational institutions, as one of the forms of internationalisation (DHET 2013). On the other hand, DHET $(2014,15)$, in the Policy for the Provision of Distance Education in South African Universities: In the context of an integrated post-school system, indicates that the "universities should be careful to link the use of supporting ICT, if relevant, to improving quality and the realities of students' contexts of learning, taking particular cognisance of the readiness of and access for remote students as the internet penetration is still only significant in urban areas". These two documents show that the DHET does not place much emphasis on or provide leadership for educational technology as one of the methods to improve teaching and learning in higher education institutions. Hence, higher education institutions are on their own to integrate educational technologies to enhance teaching and learning.

According to Van de Heyde and Siebrits $(2019,2)$, the "emerging learning technologies within the learning and teaching environments are generally underutilised in South Africa, and the need for, and use of the e-tools is of utmost importance as national higher education institutions are working towards a common goal within the context of a global education transformation". On the other hand, Bagarukayo and Kalema (2015) highlighted that few (38\%) South African public higher education institutions utilise the online learning management systems for teaching and learning technologies. The impediments that were highlighted earlier are the main barriers that prevent most South African higher education institutions from being equipped for digital teaching and learning. The UKZN is one of the few universities that has an online learning management system, although the utilisation of learning management systems such as Moodle has not been fully utilised by numerous academics. The UKZN enrolls innumerable students who come from disadvantaged schooling and poor socio-economic backgrounds who enter the university without adequate computer literacy levels. Furthermore, the university only offers Moodle training for academics, and students are left to teach themselves without the necessary levels of preparation to use or navigate the Moodle system. The study conducted by Bagarukayo and Kalema (2015), which evaluated the usage of elearning in South African universities found that students' and instructors' difficulty in using the learning management system was due to inadequate ICT skills. The assumption is that 
undertaking the Information Technology and Systems module will help students with computer literacy, but such modules do not include e-learning sessions. Introducing both students and academics to innovative educational technologies is crucial to improve both teaching and learning practices (Van de Heyde and Siebrits 2019).

In most cases, learning about technology is often confused with learning with technology. The facilitator's or educator's considerate related to these two concepts differentially affects how they approach teaching and learning concerning technology. According to Kilfoil (2015, 4), "learning with technologies has a pedagogical focus, whereas learning technologies focuses more on the technology itself"'. To ensure that there is meaningful teaching and learning taking place through e-learning, alignment of learning tasks with learning outcomes and teaching strategies must take into account the students' previous understanding and capabilities, and the technologies accessible to the students (Ng'ambi, Bozalek, and Gachago 2013).

\section{The digital literacy of students}

South Africa is a country that is marked by enormous socio-economic inequalities and extremely high levels of poverty and unemployment (StatsSA 2019). These issues contribute negatively to the student's ability to access modern technologies and gain ICT skills. Many first-year entry students, especially those who come from poor backgrounds, join the public universities with inadequate access to ICT and a lack of basic computing skills, hence, missing the critical skills required to apply digital technologies to their learning. Most of these students encounter access to the computer and the Internet for the first time when they reach universities. These challenges are ingrained by the reality that not many households have access to computers and Internet, which contributes to the inability of the students to understand education technologies for teaching and learning (Kilfoil 2015). Nevertheless, "most students entering higher education are competent users of mobile phones and have excellent social networking skills acquired through experiential learning” (Kilfoil 2015, 4). Such skills and capacities gained from social networking through mobile phones are often not authenticated or "in sync" (Ruxwana and Msibi 2018) with "institutional practices and policies, thus resulting in lost opportunities for engagement with students in learning with their own devices" (Kilfoil $2015,4)$.

As ICT is perceived as a crucial part of teaching and learning, higher education institutions now provide access to computers and educational technologies for the students. However, it should be noted that access to technology does not guarantee the use of ICT by the students for learning. Hence, student literacy in digital technologies is critical as it cuts across multidisciplinary fields where digital literacy is "embedded in the entire learning process, from 
finding information to evaluating it critically, and being able to present it electronically and responsibly" (Kennedy et al. 2010, 340). Hargittai $(2010,93)$ stipulated that while numerous "young people can operate a device, most of them are more likely to be digital 'naïves' than digital natives". This statement implies that the students must continually acquire contemporary expertise to survive and function in a digital world where the ICT is rapidly changing. On the other hand, Brown $(2012,55)$ stipulates that the higher education institutions must “reconceptualise computer literacy and move beyond a view of students' technical competence to one of the situated knowledge practices that students need to use digital tools for communication, expression and social action in the academic world".

\section{Academics and ICT skills}

As noted earlier, students must possess relevant ICT skills to ensure the effective implementation of online teaching and learning. Equally so, the facilitators or lecturers using educational technologies must possess appropriate ICT expertise to effectively execute educational technologies. Sometimes both students and facilitators view the ever-changing technologies as a daunting task to be utilised in education. Kreber and Kanuka (2006) stipulate that educational technologies sometimes harm numerous academics who are inexperienced in their use when they are appointed, so they "base their understanding of effective learning on what they had experienced during their student life" (Nyawo 2021, 220). Hence, such academics be likely to pass on their outdated beliefs of teaching to these modern educational technologies as a guide to their teaching practices. Therefore, professional support and development opportunities are vital to help academics to engage in "pedagogical problem solving" when they implement new educational technologies within their institutions. According to Tilghman $(2011,34)$, to "facilitate online assessment, the lecturers must construct successful assessment strategies and frameworks that are specifically designed for online learning environments". On the other hand, Gikandi, Morrow, and Davis $(2011,2334)$ stipulate that "educational technologies require educators to rethink online pedagogy to achieve effective formative assessment strategies that can support meaningful higher-order (or deep) learning and its assessment”.

\section{Blended learning}

Due to the rise of the number of students entering universities in South Africa, higher education institutions must discover innovative methods to engage effectively in teaching and learning despite large classes. According to Padayachee, Wagner-Welsh, and Johannes $(2018,212)$, the "advances in technology, and the new ways in which our students learn, compel us to integrate 
technology into our teaching and learning environment".

Blended learning refers to the thoughtful incorporation of directly or in-person classroom experiences with online educational improved technology experiences (Kilfoil 2015). Blended learning is of crucial value in sizeable classes where academics interact with the students at all time (Gedik and Kiraz 2012). Such benefits can be seen where the academics can better manage teaching environments with the learning management system by automatically marking formative assessments and giving instant feedback to the students, collecting assignments, using grading system that is integrated, tracing improvement, and establishing warning systems for late submission by students. Blended learning presents certain fundamental challenges to students. Such challenges include personal and cultural obstacles, practical obstacles, increased workload and time management (Gedik and Kiraz 2012). These "challenges could also apply to lecturers' experiences of blended learning” (Nyawo 2021, 223).

\section{Online assessment}

Assessment is crucial as it has a substantial influence on learning, and it is at the "core of formal higher education" (Gikandi et al. 2011, 2333). On the other hand, Crews and Curtis $(2010,868)$ indicate that "assessment and feedback form a significant part of practitioners' workloads which, with increased numbers, reduced budgets and higher learner expectations remains to be a matter of concern" for several HEIs. To afford students with opportunities to validate their emerging abilities and get the necessary assistance to enhance their learning, therefore, the processes of teaching and learning are bound to be assessment-centered.

For the past decade, studies on the online assessment and blended learning have grown rapidly (Pachler et al. 2010; Zuckweiler 2012; Spivey and McMillan 2014; Kuriakose and Luwes 2016), but the research that investigates the impacts or advantages of the online assessment techniques, and the perceptions of learners and teachers on the online assessments are still needed. Pachler et al. $(2010,716)$ utilised the term "formative e-assessment, which they defined as the use of ICT to support the iterative process of gathering and analysing information about student learning by teachers as well as learners and of evaluating it concerning prior achievement and attainment of intended, as well as unintended learning outcomes". Baleni $(2015,229)$ states that "effective amalgamation of formative assessment in online learning environments has the prospective to offer a suitable organisation for continuous significant collaborations among students and the lecturer and nurture the development of effective learning communities to enable evocative learning and its assessment".

Online assessment has strengthened the evaluation of student results and enabled them to get instant feedback (Gilbert, Whitelock, and Gale 2011). Online assessment and learning can 
have distinct forms, such as digitising paper-based systems, automatic administrative procedures, and setting online assessments. Online assessments provide numerous advantages to both students and academics. Amongst others, this includes providing instant feedback, assisting the academics to enhance the standard of critique or criticism for the students, and allowing higher education institutions to overcome save resources such as time, paper, photocopying and ink (Ridgway, McCusker, and Pead 2004; Crews and Curtis 2010; Eljinini et al. 2012; Way 2012; Padayachee et al. 2018; Alruwais et al. 2018).

Nevertheless, online assessment in higher education also has various challenges. Numerous researchers such as Donovan, Mader, and Shinsky (2007); Way (2012); Crews and Curtis (2010); and Alruwais et al. (2018), have highlighted the following challenges in the implementation of online assessment: students' lack of experience with the educational technologies; accessibility of computer and internet; poor technical infrastructure development, especially in developing countries; strenuous in recording and modifying questions with open student response such as explaining things; certain facilitators being unacquainted with technology, or the majority of them using online assessment for the first time; and lack of institutional support for educational technologies. According to Kauffman (2015), the students' perceptions, experiences and fulfilment with assessments conducted online are connected to several learner achievement factors such as "self-regulation, time management, self-evaluation and prompt feedback on performance, amongst others".

\section{Mishra and Koehler's TPCK framework}

This study has utilised Mishra and Koehler's TPCK framework. The foundation of this framework is the apprehension that teaching and learning is an extremely multifaceted activity that draws on numerous kinds of knowledge, such as, content, pedagogical, and technological knowledge, amongst others (Mishra and Koehler 2006). Therefore this framework is "concerned with the complex interaction between content, pedagogy, and technology, which can be defined as pedagogical content knowledge, technological content knowledge, technological pedagogical knowledge - all three taken together as technological pedagogical content knowledge (TPCK)" (Mishra and Koehler 2006, 1026). The authors (Mishra and Koehler 2006, 1029) of this framework stipulated that the TPCK is the "basis of effective teaching with technology, requiring an understanding of the representation of concepts using technologies; pedagogical techniques that use technologies in constructive ways to teach content; knowledge of what makes concepts difficult or easy to learn and how technology can help redress some of the problems that students face; knowledge of students' prior knowledge and theories of epistemology; and knowledge of how technologies can be used to build on 
existing knowledge to develop new epistemologies or strengthen old ones".

\section{RESEARCH METHODOLOGY}

This is a deductive study that utilises existing theory to assess the use of online learning in a higher education institution in South Africa. The research has adopted a quantitative research approach that relied on a self-administered questionnaire for collecting data. The collected data entered into SPSS and analysed through various statistical analysis/tests in relation to the study objectives. The population of the study was defined by the class register containing details of 212 students registered for second year-level, the Introduction to Public Sector Human Resource Management module within the Discipline of Public Governance. The data collection tool was sent to the entire population. This module was selected as it was the only module in the Discipline that offered an online formative assessment. The questionnaires were distributed to all 212 students registered for the module mentioned above, but only 107 returned the completed questionnaires.

The above methods were chosen to capture the perceptions of students on the online platforms that the university has been using in order to make generalisations that might assist other institutions that are rolling out online learning or plan to use a similar platform in the future to avoid delay of academic programmes as a result of unforeseen events. A return rate of 51 per cent was deemed acceptable by the research considering that all the students that were present on the day of data collection completed the questionnaire. The above also confirms the average attendance rate of this class, which was also verified by the signed daily class register.

\section{DATA PRESENTATION AND DISCUSSION: STATUS QUO (UKZN, DISCIPLINE OF PUBLIC GOVERNANCE)}

Indeed, times have changed; students in South Africa are now required to access electronic resources and participate in learning through a digital platform. The University of KwaZuluNatal uses an online platform called Moodle to share lecture resources, host forum discussions and administer assessments.

The sample comprised of undergraduate students in the Discipline of Public Governance. Many of the respondents were aged between 19 and 22 years. Students in this class were studying towards different degrees, but the majority were studying toward a Bachelor of Administration degree, as the module falls under this Discipline. Close to 80 per cent of the students who responded to the questionnaire were in their second year of studying, as indicated in Table 1. 
Table 1: Participants' year of study

\begin{tabular}{|l|l|c|c|}
\hline \multicolumn{2}{|c|}{} & Frequency & $\%$ \\
\hline Valid & First Year & 1 & .9 \\
\cline { 2 - 4 } & Second Year & 79 & 73.8 \\
\cline { 2 - 4 } & Third Year & 13 & 12.1 \\
\cline { 2 - 4 } & Fourth Year & 1 & .9 \\
\cline { 2 - 4 } & Fifth Year Plus & 2 & 1.9 \\
\cline { 2 - 4 } & Total & 96 & 89.7 \\
\hline Missing & System & 11 & 10.3 \\
\hline Total & & 107 & 100.0 \\
\hline
\end{tabular}

The data were collected from students registered for a second-year module. However, some students selected this module as an elective. Thus, there were students at different levels in their degrees of choice. The above information is essential as it shows that the students that participated in the study were not using the online university platform for the first time. It is assumed that they already had some experience using online university platforms. The participants were thus aware that they were required to have access to the Internet to be able to complete online assessments and access lecturer resources, as they were not first-time users of the Moodle platform.

The gender demographics resemble a typical classroom in South Africa, where female students dominate. Male participants were 28 per cent, female 76 per cent and other 2 per cent.

Table 2: Race groups of participants

\begin{tabular}{|l|l|c|c|}
\hline \multirow{2}{*}{ Valid } & African & Frequency & $\%$ \\
\cline { 2 - 4 } & Indian & 69 & 64.5 \\
\cline { 2 - 4 } & White & 18 & 16.8 \\
\cline { 2 - 4 } & Coloured & 1 & .9 \\
\cline { 2 - 4 } & Total & 2 & 1.9 \\
\hline Missing & System & 17 & 84.1 \\
\hline Total & 107 & 15.9 \\
\hline
\end{tabular}

The above figures partially bear a slight resemblance to demographic statistics of the population nationally. According to Statistics South Africa $(2011,17)$, the national census population demographics reflect that the country has " $76.4 \%$ Black African, 9.1\% white, $8.9 \%$ coloured, $2.5 \%$ Indian/Asian, and $0.5 \%$ other/unspecified people groups". The Department of Higher Education Training published a report indicating the demographics of students in the higher education sector in $2018(2018,13)$ showing that students enrolled in public HEIs were “Africans $(71.9 \%$ or 701482$)$, followed by white students $(15.6 \%$ or 152489$)$, coloured students (6.3\% or 61963$)$ and Indian/Asian students (5.2\% 50 450)." At the university level, 
UKZN (2018) has 46562 students registered, of which about 71 per cent of the student are African, 22 per cent are Indian/Asian, 2 per cent are coloured and the other races make up the remaining percentage. Also, at the class level being studied, the dominant racial group is African, with 64.5 per cent followed by Indian and coloured, as in the table above. Statistics South Africa published a report of sustainable development goals 2019 that shows that there are high numbers of South Africans living in rural areas; most black South Africans live in rural areas with limited access to the Internet. However, the university provides connected computers for students who do not have Internet access.

Where do students access the online university platform? The results show that 22.4 per cent of the students access university platforms from home, 0.9 per cent from internet cafés, 11.2 per cent from mobile phones, 40.2 per cent use university computer labs, and 25.2 per cent from other sources. Most of the students use computer labs for reliable Internet access.

In addition to the above, the students were asked to list their uses of the online teaching and learning platforms.

Table 3: Participants' use of the online platform

\begin{tabular}{|l|c|c|}
\hline & Yes & No \\
\hline Use for Lecture Slides & $94.3 \%$ & $5.7 \%$ \\
\hline Use for Discussion Forum & $66.0 \%$ & $34.0 \%$ \\
\hline Use for Online Assessment & $66.0 \%$ & $33.0 \%$ \\
\hline
\end{tabular}

It is important to note that students face several challenges using digital platforms; 94.3 per cent of the students used the Moodle platform to access Lecture slides, 66 per cent to participate in discussion forums, and 66 per cent to complete the online assessments. Concerning their use of the online teaching and learning platforms, the students were asked to indicate their experiences. Table 4 captures the experiences of the students using the online platform.

Table 4: Participants' experience rating of the online platform

\begin{tabular}{|l|c|c|}
\hline & Frequency & $\%$ \\
\hline Excellent & 9 & $8.4 \%$ \\
\hline Good & 42 & $39.3 \%$ \\
\hline Neutral & 19 & $17.8 \%$ \\
\hline Bad & 13 & $12.1 \%$ \\
\hline Poor & 23 & $21.5 \%$ \\
\hline Total & 106 & $99.1 \%$ \\
\hline Missing & 1 & $.9 \%$ \\
\hline Total & $\mathbf{1 0 7}$ & $\mathbf{1 0 0 . 0 \%}$ \\
\hline
\end{tabular}


Students were requested to rate their experiences with the online university platform and, as in the table above, 8.4 per cent of the students reported an excellent experience, and the majority had a good experience. The above is likely because most of the students were not using the online platform for the first time.

Table 5: Participants' types of computer literacy training

\begin{tabular}{|l|c|c|}
\hline & Frequency & $\%$ \\
\hline Typing & 1 & .9 \\
\hline University Module & 84 & 78.5 \\
\hline None & 6 & 5.6 \\
\hline Self-Taught & 14 & 13.1 \\
\hline Others & 2 & 1.9 \\
\hline Total & 107 & 100.0 \\
\hline
\end{tabular}

Many students learned to use computers at the university; Table 5 shows the type of training the students had received. Most students received training through a university module and 13.1 per cent taught themselves how to use computers.

Students were given online assessments during the study, which were timed. A total of 107 students attempted the assessments. A total of 11.2 per cent of the participants completed the assessments, while 82.2 per cent could not complete the assessments. The reasons for not completing online assessments are captured in Table 6.

Table 6: Participants' reasons for not completing online assessments

\begin{tabular}{|l|c|c|}
\hline \multicolumn{1}{|c|}{ Reasons given } & Yes & No \\
\hline Limited Time & $80.2 \%$ & $19.8 \%$ \\
\hline Slow Typing & $48.1 \%$ & $51.9 \%$ \\
\hline Weak WIFI connection & $11.3 \%$ & $88.7 \%$ \\
\hline Unpreparedness & $7.5 \%$ & $92.5 \%$ \\
\hline Computer illiteracy & $3.8 \%$ & $95.3 \%$ \\
\hline
\end{tabular}

The majority $(80 \%)$ of the participants agreed that they could not complete the online assessments on time and felt that the time was too limited. Almost half (48\%) of the participants agreed that they did not complete the assessments because of typing at a slow pace.

A very high percentage of 88.7 per cent of participants disagreed that they did not complete the assessments because of poor internet connection. A high percentage of students $(92.5 \%)$ agreed that they were prepared for the online assessments, and 95.3 per cent of the students considered themselves to be computer literate.

The chart below shows students' competencies in chatting, browsing the Internet, 
accessing emails and typing. All these are necessary computing competencies that a student should possess to be able to interact with online learning platforms.

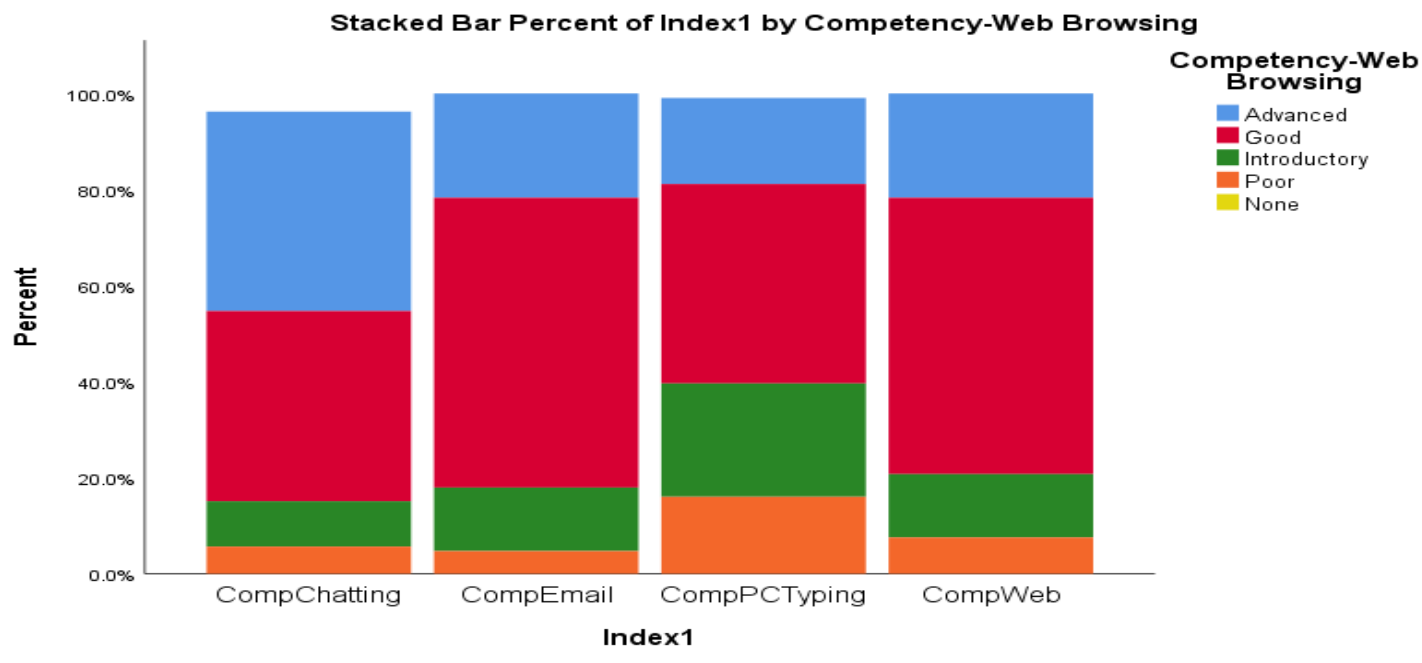

Figure 1: Students' competency in specific skills

Figure 1 shows that a high percentage of students could chat, access emails, type, and browse the Internet. In all qualities indicated in the above figure, more than 60 per cent of the students considered themselves to have above-average skills.

The students were asked to rate their experience with using the UKZN online learning platform Moodle in navigating through pages, instructions, online assessment, ease of use, viewing feedback and being able to see the time remaining while completing an assessment. Table 7 represents the response from students.

Table 7: Students' experience with online platform: Moodle at UKZN

\begin{tabular}{|l|c|c|c|c|c|}
\hline \multicolumn{1}{|c|}{ Experience } & Excellent & Good & Neutral & Bad & Poor \\
\hline Navigation/Browsing pages & $29.2 \%$ & $39.6 \%$ & $22.6 \%$ & $6.6 \%$ & $1.9 \%$ \\
\hline Instructions & $32.1 \%$ & $34.0 \%$ & $25.5 \%$ & $6.6 \%$ & $1.9 \%$ \\
\hline Online Assessment & $12.4 \%$ & $18.1 \%$ & $38.1 \%$ & $21.0 \%$ & $10.5 \%$ \\
\hline Moodle Experience - Use and Comfort & $17.9 \%$ & $23.6 \%$ & $34.9 \%$ & $16.0 \%$ & $7.5 \%$ \\
\hline Viewing results and feedback & $11.3 \%$ & $27.4 \%$ & $24.5 \%$ & $16.0 \%$ & $20.8 \%$ \\
\hline Seeing time remaining & $12.3 \%$ & $24.5 \%$ & $17.0 \%$ & $21.7 \%$ & $24.5 \%$ \\
\hline
\end{tabular}

A total of 68.8 per cent of the participants had a good to an excellent experience in navigating through the online learning platform. Students could follow the instructions: 66.1 per cent of participants had a good experience with the instructions on the Moodle platform. However, a considerably high percentage of students $(31.5 \%)$ did not have a good experience with online 
assessments. As indicated in this study, many of the students were not able to complete the online assessment. It is a concern that Table 7 reflects that 38.1 per cent and 34.9 per cent of the students had a neutral experience with online assessment and "ease of use", respectively. Therefore, there is a need to improve students' experience in terms of using online learning platforms and taking online assessments. Feedback is a significant part of learning; however, not enough students think that feedback through the online system is useful. Furthermore, Table 7 reflects that only 38.7 per cent of the students had a good or excellent experience when viewing online assessment feedback. Online assessments can be timed, and the one that was sent to the sample was timed. About 46.2 per cent of the participants (as indicated in Table 7) had bad to poor experiences with seeing the remaining time while they completed the online assessment.

Table 8: Students' perceptions of Moodle teaching and learning system at UKZN

\begin{tabular}{|l|c|c|c|c|c|}
\hline & $\begin{array}{c}\text { Strongly } \\
\text { Agree }\end{array}$ & Agree & Neutral & Disagree & $\begin{array}{c}\text { Strongly } \\
\text { Disagree }\end{array}$ \\
\hline Provides immediate feedback & $13.2 \%$ & $46.2 \%$ & $27.4 \%$ & $11.3 \%$ & $1.9 \%$ \\
\hline Better than offline approach & $11.3 \%$ & $17.9 \%$ & $13.2 \%$ & $19.8 \%$ & $37.7 \%$ \\
\hline Assessment consistent with teaching style & $3.8 \%$ & $25.7 \%$ & $40.0 \%$ & $15.2 \%$ & $15.2 \%$ \\
\hline Contemporary method & $3.8 \%$ & $26.7 \%$ & $58.1 \%$ & $7.6 \%$ & $3.8 \%$ \\
\hline
\end{tabular}

Most of the participants (59.4\%) perceived the Moodle Teaching and Learning System as a platform that provided immediate feedback. Only 29.2 per cent of the participants believed that the online platform was better than pen and paper methods. This shows that students still prefer to complete assessments offline. The students still felt that there was some consistency between the way they are taught and online assessment: a total of 74 per cent of them did not agree that online assessment is consistent with the way they are taught (Table 8). It was alarming to establish that some students did not perceive the Moodle Teaching and Learning System platform to be a contemporary method of learning.

\section{DISCUSSION}

According to Al-Rifaee (2018), e-learning offers an "exciting and inspiring learning environment for both teachers and students, as the determinants of time and space are eliminated, in addition to allowing students" to learn in a manner that relates to their daily life. E-learning works well if both lecturers and students are computer literate and connected to the Internet. However, in South Africa, that is not the case. The country is marked by enormous socio-economic inequalities and extreme levels of poverty and unemployment. The undergraduate classes are attended by young people who are likely to be unemployed and most 
of them are from rural communities with limited network coverage and limited access to WiFi.

Brown (2012) states that the higher education institutions must reconceptualise computer literacy and progress beyond a perspective that students should possess the technical knowledge to one of the situated knowledge practices. The students should efficiently utilise the educational multimedia instruments to communicate, interact and voice their concerns in the academic world. University undergraduate students should be required to attend the computer literacy module, as there is a high correlation between attending computer-related modules and computer literacy. The participants confirmed the above, and most of them reported connecting to the Internet through the university LAN; 88.7 per cent of participants disagreed that they did not complete the assessment because of poor internet connection. The university is providing a reliable online connection to the students; however, in cases of events that require students to vacate the university premises, the students might move to locations with minimal Internet connection.

According to Gilbert et al. (2011), the benefits of online assessment extend beyond immediate feedback and distance coverage. Online learning provides students with opportunities to validate their emerging abilities and skills and access the necessary assistance to enhance their learning. Therefore, assessment-centred methods should be utilised for teaching and learning processes. If done correctly, Baleni (2015) asserts that online learning environments have the prospect of offering "continuous significant collaborations among students and the lecturer and nurturing the development of effective learning to enable reminiscent learning and its assessment." However, students need to be ready for this shift in the way of learning. The results from the study show that 92 per cent of the students were prepared for the online assessment and that 95 per cent of the student considered themselves to be capable of completing an online assessment.

Over 60 per cent of the participants considered themselves to be computer literate by classifying their computer skills to be above the introductory level. This is because they had completed a computer module at the university and some considered themselves self-taught. A high number of students had a good experience navigating through the online learning platform. Therefore, an intervention that could work for the university is to make it compulsory for all students to attend the computer literacy module at the beginning of their academic journey and prepare them for online learning and online assessment.

Based on the assessment of the sample, the challenge seems to be with online assessment: 82.2 per cent of the students did not finish the online assessment and 31 per cent of the students reported having a bad experience with the online assessment. Students are computer competent, and they can search for resources and learn online; however, they are not trained to be assessed 
online. Thus, the results suggest that there is a need to improve students' experience when using the online learning platforms and taking an online assessment. Online platforms that show remaining time while students are writing are intimidating. This is reflected by a considerably high percentage of participants who rated their experience with timed online assessment as bad to poor. At first, environmental concerns led to universities becoming paperless and students were required to submit assignments online. The current circumstances, including the COVID19 outbreak and the fourth industrial revolution, are leading to a situation where learning and assessment should be accessible online.

The university's academic programme would not be heavily impacted by the unforeseen events of 2019 and 2020, such as student protests and the outbreak of COVID-19, if it were to subscribe to the use of digital platforms. Authors have highlighted many online learning challenges HEIs that are also experienced at the University of KwaZulu-Natal. Ridgway et al. 2004; Donovan et al. 2007; Way 2012; Crews and Curtis 2010; Alruwais et al. 2018 assert that when the university migrates to online teaching and learning, there are certain challenges that the institution experiences. Such challenges include the inexperience of students with computers or with the online assessment processes; accessibility of computers and Internet; poor technical infrastructure development, especially in developing countries; burdensome in recording and modifying questions with open responses; facilitators who are computer illiterate; and lack of institutional support on educational technologies.

It is worth noting that the challenges are more pressing when an institution is still in the early stage of using online learning. The track record of many institutions using online learning shows that after a while, most challenges are addressed. Therefore, the shift to online learning might be difficult to manage if the institution is responding to a once-off event or crisis such as a pandemic or a students' protest. However, it would be manageable if it becomes part of the institution's process, culture, and policy. In its entirety, rolling out online learning to a traditional learning institution located in an economy with severe social-economic challenges might require students to be assisted with connecting to the Internet, ongoing training sessions and culture change.

Pedagogy remains the centre of learning. Gikandi et al. $(2011,2334)$ stipulate that "educational technologies require educators to rethink online pedagogy to achieve effective formative assessment strategies that support meaningful higher-order (or deep) learning and its assessment." There is a need to change the pedagogy chosen by the facilitator, as a total of 74 per cent of the participants could not agree that the style of teaching is in the class was consistent with the online assessment. Online learning is not changing the role of the university, but it is changing how the university delivers teaching and learning, and the proper pedagogy should be 
applied. Blended learning, as alluded to by Padayachee et al. (2018), enables the use of technology and the application of up-to-date learning methods by students, require lecturers to ensure that technology is incorporated into the teaching and learning environment. Students are contentedly using technology for social purposes, and they learn through this behaviour. Thus, lecturers are pushed to find a pedagogy that activates blended learning. The TPCK framework has suggested migrating to learning the successful use of technology. The framework guides effective teaching and requires (Mishra and Koehler 2006, 1029):

- An understanding of the representation of concepts using technologies;

- Educational methods that allow for the application of technologies in positive ways to deliver and facilitate content;

- An understanding of why certain concepts are easy or not easy to learn and what is the role of technology in correcting certain issues that learners experience (allowing the facilitator to use platforms such as Youtube, Tiktok, and Facebook);

- An understanding of "students' prior knowledge and theories of epistemology" (Mishra and Koehler 2006, 1029); and

- The use of "technologies to build on existing knowledge to develop new epistemologies or strengthen old ones.” (Mishra and Koehler 2006, 1029)

There is a need to shift away from a situation where facilitators and learners prefer to gather in a lecture venue to engage with peers or listen to lectures. Continuous improvement in educational technologies helps reduce such limitations, however, and playing a massive role in the educational transformation within higher education institutions. The current online learning conversation will eventually translate to strategies that will be implemented in the near future, and the students need some training and technical assistance to be fully on board with the new developments.

\section{CONCLUSION}

Some universities have measures in place that signify institutional readiness for online learning, as suggested by the case study. However, there are social ills that make it difficult to implement effective virtual learning. The article notes that, as much as institutions are at different levels of readiness, there is a great need to capture the status quo of a typical class in HEIs to alter the culture of teaching and learning. Online learning does not change the purpose of the university but the mode of learning delivery. How the higher education institutions operate remains uninterrupted: students are still required to attend classes at the selected or arranged venue and 
time to listen to the facilitators during teaching and learning, and the same is achieved online. The outbreak of the novel coronavirus and the continuous destruction of university academic programmes in South Africa have led to a path within which institutions must re-evaluate their processes. In the face of the fourth industrial revolution, a new university is emerging that teaches, supervises, researches, and services communities in a distinct way. The challenges the world has presented to the institutions require them to alter their processes to be valuable to the communities with minimal interaction.

The current circumstances are leading to a situation where learning and assessment should be offered online as a result of events such as the COVID-19 pandemic and the fourth industrial revolution. However, in countries like South Africa, social issues should be tackled to shift to online learning successfully. The study results also assert that the shift to online learning might be difficult to manage if the institution is responding to a once-off event such as a pandemic or a students' protest. However, it would be manageable if it became part of the institution's process, culture, and policy. Thus, the study notes that an economy with severe social-economic challenges might require students to be assisted with connecting to the Internet, ongoing computer and online training and culture change. Online learning might call for a change in the pedagogy chosen by the facilitator.

\section{REFERENCES}

Al-khalifa, H. 2010. "From e-learning management systems to personal learning environments." Journal of the Arabian Gulf message 3(2): 15-29.

Al-Rifaee, A. J. F. 2018. "The reality of the use of the University of Jordan's students of the Moodle System in the process of learning and instruction from their perspectives." International Journal of Instructional Technology and Distance Learning 15(4-5-6): 1-74.

Alruwais, N., G. Wills, and M. Wald. 2018. "Advantages and Challenges of Using e-Assessment." International Journal of Information and Education Technology 8(1): 34-37.

Al-zabun, M. 2015. "The Effect of Teaching on the Use of Electronic Courses in the Achievement of Jordanian University Students in Computer Skills and in the Development of their Self-Learning and Social Communication Skills." Unpublished Dissertation, University of Jordan: Amman, Jordan.

Bagarukayo, E. and B. Kalemo. 2015. "Evaluation of e-learning usage in South African universities: A critical review." International Journal of Education and Development using Information and Communication Technology 11(2): 168-183.

Baleni, Z. 2015. "Online formative assessment in higher education: Its pros and cons." The Electronic Journal of e-learning 13(4): 228-236.

Brown, C. 2012. "University students as digital migrants." Mobility, Language, Language and Literacy 14(2): 41-61.

Crews, T. B. and D. F. Curtis. 2010. "Online course evaluations: Faculty perspective and strategies for improved response rates." Assessment \& Evaluation in Higher Education 36(7): 965-878.

Department of Higher Education and Training. 2013. White Paper for Post-School Education \& Training: Building an expanded, effective ad integrated post-school system. Government Gazette. 
Pretoria.

Department of Higher Education and Training. 2014. Policy for the Provision of Distance Education in South African Universities: In the context of an integrated post-school system. Government Gazette. Pretoria.

Department of Higher Education Training. 2018. DHET: Research, Coordination, Monitoring and Evaluation.

http://www.dhet.gov.za/Research\%20Coordination\%20Monitoring\%20and\%20Evaluation/6 DHET\%20Stats\%20Report_04\%20April\%202018.pdf.

DHET see Department of Higher Education and Training.

Dobrzaski, L. A., Z. Brytan, and F. Brom. 2007. "Use of e-learning in teaching Fundamentals of Materials Science." Journal of Achievements in Materials and Manufacturing Engineering 24(2): 215-218.

Donovan, J., C. Mader, and J. Shinsky. 2007. "Online vs. traditional course evaluation formats: Student perceptions." Journal of Interactive Online Learning 6: 158-180.

Eljinini, M., S. Alsamarai, S. Hameed, and A. Amawi. 2012. "The Impact of E-assessments System on the Success of the Implementation Process." International Journal of Modern Education and Computer Science 11: 76-84.

Gedik, N. and E. Kiraz. 2012. "The optimum blend: affordances and challenges of blended learning for students.” Turkish Online Journal of Qualitative Inquiry 3(3): 102-117.

Gikandi, J. W., D. Morrow, and N. E. Davis. 2011. "Online formative assessment in higher education: A review of the literature." Computers \& Education 57(2011): 2333-2351.

Gilbert, L., D. Whitelock, and V. Gale. 2011. Synthesis report on assessment and feedback with technology enhancement. https://eprints.soton.ac.uk/273221/1/Synthesis\%2520report\%2520on\% 2520assessment $\% 2520$ and\%2520feedback\%2520Final\%2520Report\%2520July\%25202011.pdf.

Gorghiu, G., L. M. Gorghiu, A. M. Suduc, M. Bîzoi, C. Dumitrescu, and R. L. Olteanu. 2009. "Related aspects to the pedagogical use of virtual experiments." Research, Reflections and Innovations in integrating ICT in education, 2, FORMATEX, 809-813.

Hargittai, E. 2010. Digital na(t)ives? "Variation in internet skills and uses among members of the "Net Generation'." Sociological Inquiry 80(1): 92-113.

Isabirye, A. K. and N. Dlodlo. 2014. "Perceived Inhibitors of Innovative E-learning Teaching Practice at a South African University of Technology." Mediterranean Journal of Social Sciences 5: 390398.

Jordaan, A., and A. van der Merwe 2015. "Best practices for learning analytics initiatives in higher education." https://repository.up.ac.za/handle/2263/50956.

Kauffman, H. 2015. "A review of predictive factors of student success in and satisfaction with online learning." Research in Learning Technology 23: 26507

Kennedy, G., T. Judd, B. Dalgarno, and J. Waycott. 2010. Beyond natives and immigrants: Exploring types of net generation students. Journal of Computer Assisted Learning 26(5): 332-343.

Kilfoil, W. R. 2015. Moving beyond the hype: A contextualised view of learning with technology in higher education. Pretoria: Universities South Africa.

Kreber, C. and H. Kanuka. 2006. "The scholarship of teaching and learning and the online classroom." Canadian Journal of University Continuing Education 32(2): 109-131.

Kuriakose, R. B. and N. Luwes. 2016. "Student Perceptions to the Use of Paperless Technology in Assessments - A Case Study using Clickers." Procedia - Social and Behavioral Sciences 228: 78-85.

Mashau, P. 2017. "Learning Technology in a Postgraduate Class in South Africa: Experiences and Learnings at the University of KwaZulu-Natal, GSBL." International Journal of Educational Sciences 18(1-3): 65-72.

Mashau, P., Z. Fields, and J. C. Nyawo. 2019. "Evaluation of South African universities' collaborations 
as drivers of entrepreneurship." African Renaissance 16(1): 139-165.

Mishra, P. and M. J. Koehler. 2006. "Technological pedagogical content knowledge: A framework for teacher knowledge." Teachers College Record 108(6): 1017-1054.

Mlitwa, W. and J. W. G. D. Van Belle. 2011. "Mediators for lecturer perspectives on learning management systems at universities in the Western Cape, South Africa." In Proceedings of the Pacific Asia Conference on Information Systems (PACIS 2011). Brisbane, Australia. Brisbane: A.I.S. Electronic Library.

Ng'ambi, D., V. Bozalek and D. Gachago. 2013. Empowering educators to teach using emerging technologies in higher education - a case of facilitating a course across institutional boundaries. Proceedings of the 8th International Conference on e-learning. Cape Peninsula University of Technology, 27-28 June 2013.

Nyawo, J. C. 2021. “Comparison of Undergraduate Students' Perception of Tutorials Before and During the COVID-19: A Case of the University of Kwazulu-Natal in the Discipline of Public Governance." International Journal of Higher Education 10(2): 217- 228.

OERAfrica. 2014. Case studies: delivering eLearning in South Africa. http://www.oerafrica. org/supporting-distance-learners/case-studies-delivering-elearning-south-africa.

Pachler, N., C. Daly, Y. Mor, and H. Mellar. 2010. "Formative e-assessment: Practitioner cases." Computers \& Education 54: 715-721.

Padayachee, P., S. Wagner-Welsh, and H. Johannes. 2018. "Online assessment in Moodle: A framework for supporting our students." South African Journal of Higher Education 32(5): 211-235.

Ridgway, J., S. McCusker, and D. Pead. 2004. Literature review of e-assessment. Bristol.

Rooney, J. E. 2003. "Blending learning opportunities to enhance educational programming and meetings." Association Management 55(5): 26-32.

Ruxwana, N. and M. Msibi. 2018. "A South African university's readiness assessment for bringing your own device for teaching and learning." South African Journal of Information Management 20(1): $1-16$.

Spivey, M. F. and J. J. McMillan. 2014. "Classroom versus Online Assessment.” Journal of Education for Business 89(8): 450-456.

Statistics South Africa. 2011. “Census 2011.” https://www.statssa.gov.za/publications/P03014/ P030142011.pdf.

Statistics South Africa. 2019. "Sustainable development goals." http://www.statssa.gov.za/? Page_id $=739 \& i d=5$.

StatsSA see Statistics South Africa.

Ting-Sheng Weng, T. S. and H. C. Lin. 2007. "The Study of E-learning for Geographic Information Curriculum in Higher Education." Applied Computer Science (ei): 618-623.

Tilghman, S. B. 2011. Designing and developing online course assessments. Review of Higher Education and Self-learning 4(9): 31-34.

Van de Heyde, V. and A. Siebrits. 2019. "The ecosystem of e-learning model for higher education." South African Journal of Science 115(5/6): 1-6.

Venter P. M. J. van Rensburg and A. Davis. 2012. Drivers of learning management system use in a South African open and distance learning institution. Australasian Journal of Educational Technology 28(2):183-198.

Wankle, C. (Ed.). 2011. Teaching arts and science with new social media. New York: Emerald Group Publishing Limited.

Way, A. 2012. "The use of e-assessments in the Nigerian higher education system." Turkish Online Journal of Distance Education 13(1): 140-152.

Weaver, D., C. Spratt, and C. S. Nair. 2008. "Academic and student use of a learning management system: Implications for quality." Australian Journal of Educational Technology 24(1): 30-41. 
Xing, B. and T. Marwala. 2017. "Implications of the fourth industrial age for higher education." The Thinker Issue 73(3): 10-15.

Zuckweiler, K. M. 2012. "Using technologies to enhance student learning in the online classroom." Decision Line: Decision Sciences Institute 43: 6-8. 